\title{
Social Media in Azorean Organizations: Policies, Strategies and Perceptions
}

\author{
Nuno Filipe Cordeiro \\ Business and Economics Department \\ University of the Azores \\ Ponta Delgada, Portugal \\ Flávio Tiago \\ Business and Economics Department \\ University of the Azores \\ Ponta Delgada, Portugal
}

\author{
Teresa Tiago \\ Business and Economics Department \\ University of the Azores \\ Ponta Delgada, Portugal \\ Francisco Amaral \\ Business and Economics Department \\ University of the Azores \\ Ponta Delgada, Portugal
}

\begin{abstract}
Social media have brought new opportunities, and also new challenges, for organizations. With them came the rise of a new context of action, largely influenced by the changing habits and the behavior of the consumer. The purpose of the following research is to analyze the views and strategies embraced by Azorean organizations, as well as the perceptions arising from the use of social media.
\end{abstract}

For this study, a quantitative type of research, of a descriptive nature, was chosen, using an online survey. A total of 232 valid surveys obtained led to a range of perceptions about the use of social media. The study hypotheses were verified using the Kruskal-Wallis analysis.

The results demonstrate that the majority of organizations involved in the study already use social media and that almost all of them use Facebook. The main reasons are to reach a wider audience, to increase notoriety and to communicate with customers. The most relevant difficulty felt after joining the social media is the lack of resources and availability. Marketing initiatives and content creation are the most-used activities. Remarkably, more than half don't have a defined strategy, nor use measuring instruments to assess their presence. However, they consider that social media enhance their performance.

Social media is a widely studied topic from the consumer's point of view, but there is still little investigation from an organizational perspective. This work sought to contribute to the knowledge about the use and involvement of organizations in social media, especially in the peripheral context.

Keywords-Internet; Web 2.0; Social Media; User Generated Content

\section{INTRODUCTION}

Today, access to the Internet is greatly facilitated and related technologies are in a continuous evolution. Social media constitute one of these evolutions, and are very popular among users. Sites like Facebook, YouTube, Twitter and others have attracted users around the world, who spend a considerable part of their time on them [1].
These sites have been modifying the habits and behaviors of better-informed consumers. One property that contributed to success of social media was the possibility of two-way communication, allowing user content to be generated daily on these sites, without organizational control. This permitted clients to express their points of view about products and services, share experiences and provide recommendations. These content has influence on other consumers' purchasing decisions [2].

These facts piqued the interest of firms, motivating them to integrate social media into their business process [3], utilize the chance to be closer to their clients, identify their behaviors and satisfy them [2]. The literature review reveals that many studies focus primarily on the consumer perspective, and some authors and research organizations suggest that the enterprise perspective is often overlooked by social media research.

This work is about a firm's exploitations of social media to reach clients, especially in identifying which channels and activities they use, their motivations to use social media, whether they use it, which metrics are used to evaluate their presence on social media and finally, the benefits of using social media. Additionally, it tries to unveil a firm's strategies regarding social media, the investment policies and the best practices used to achieve the defined objectives.

For practical reasons, this study focuses on Azorean firms' utilizations of social media. Data gathering was conducted over e-mail with the survey sent to Azorean enterprises during February 2013.

The rest of this paper is organized as follows: Section 2 discusses the related literature reviewed for this research study. The subsequent sub-section outline the conceptual model and experimental hypothesis on which the model is based and presents methodology and discussion of the empirical findings. Section 4 describes the paper's results. The implications for organizations as well as for research and limitations and scope for future research are discussed in sections 5 and 6 respectively. 


\section{RESEARCH BACKGROUND}

On the Internet, a wide range of applications are found that meet Web 2.0 specifications, varying in degree of interactivity, context, structure and objectives. They are divided into six different classes: (i) collaborative projects like Wikipedia; (ii) blogs and micro-blogs as Twitter; (iii) content community sites similar to YouTube; (iv) massive multi-player online roleplaying games such as World Warcraft; (v) social virtual worlds like Second Life; and (vi) social networks, e.g., Facebook and LinkedIn [4].

Web 2.0 can be characterized as: (i) change to online applications in the form of services, the traditional supplier that controls the software passes to a software service without proprietary systems and emphasizes applications with userfriendly features; (ii) through users' collaboration based on their experience with applications, a continuous and incremental application development is made with the objective of added value to clients. The more users participate in this process, the more advanced applications will be; and (iii) the emergence of a new set of business models supported on consumers' market niches that are traditionally hard to reach [5].

With these social and technological developments, the Internet is no longer a simple repository of static and passive information; it becomes active and participatory. At the same time, the users' behavior changed from that of an information consumer to an active producer of content of information, i.e., User Generated Content (UGC) [6].

The term Web 2.0 and social media are used as synonyms, largely due to their proximity and interdependence, yet they are conceptually different. Social media comprise both the conduits and the content published by users interactively and organizations on sites that meet the Web 2.0 specifications [7]. So social media is characterized by participation of users, creating digital communities and the connectivity between its elements [8].

The widespread acceptance of social media by consumers has enabled them to become involved in content consumption and sharing in experiences, opinions and comments [7]. This deep consumer behavioral transformation enabled them to feel accomplished by influencing the opinions of their peers and contributing to the collective intelligence [9]. This change was visible in such way that TIME magazine elected as 2006 Person of the Year 2006, not a particular personality, but "YOU" — thereby acknowledging the millions of customers who produce information on social media [10], [11].

Studies of consumers who search for information on products and services in social media suggest that these clients have one or more features of Social Technographic profiles when surfing profiles on social sites [12], [13]:

1) Creators: Highest level. At least once a month, they publish blogs and Web pages, upload content created by them in video and audio format, and write and publish articles or stories. At the bottom are the ones who produce content.

2) Talkers: Post on Twitter and update their status on social networks at least once a week.
3) Critics: Publish ratings or reviews of products/services, commenting on blogs and forums and editing wikis. They are built on what has been published and commented.

4) Collectors: They use RSS feeds, vote on websites and add bookmarks on websites and photos. The main purpose is tantamount to storing content.

5) Participants: Maintain a profile on a social network and visit social networking sites. They are designed to relate to other people.

6) Spectators: They visualize what other produce on blogs, videos, podcast and forums.

7) Inactive: Do not practice any of the above activities.

The process of acquisition of goods and services can be outlined by the Social Feedback Cycle model that consists of four steps: (i) awareness; (ii) phase of consideration (one looks at all the attributes that influence the purchase); (iii) purchase stage; (iv) post-purchase considering the social aspects of the Web and the impact of word of mouth (divulge your experience with the product / service purchased) that can influence the process of attracting future customers [14].

Utilization of social media changed the way organizations do business. They began to communicate with consumers, organizations and suppliers, thereby enabling the creation and management of customer relationships as well as increasing perception of consumer needs. The proper management of these relationships helps eliminate damage to reputation and loss of revenues due to unhappy customers. Indeed, companies can take advantage of those clients that are satisfied by sharing their enthusiasm and experience in social media [15].

Many organizations utilized the features provided by Web 2.0 tools to improve internal communication and leverage the collective intelligence of the organization. Given the features of blogs, wikis, RSS feeds, etc., they are the most-used Web 2.0 tools to facilitate communication, collaboration and sharing of internal information [16], [17].

An organization, to have a presence on social media, should initially define an implementation strategy. This strategy can pass through the POST method (People Objective Strategy Technology) [12]:

1) Define the target audience and understand their activities

2) Set goals in social media by listening to the clients, promoting the brand, energizing consumers and identifying how they can influence and support potential customers using wikis and forums, and finally engage customers in developing new products / services

3) Define a strategy for attaining those objectives and plan the relationships with the clients on social media

4) Define the social media types where they will be.

The presence of organizations on social media enables them to improve credibility with consumers, strengthen ties of loyalty in the emotional and behavioral dimensions, and achieve greater visibility and a much wider audience at lower costs. Exploring the UCG, companies have the ability to better understand consumers, gather information about the strengths 
and weaknesses of their products / services and take advantage of "word of mouth." Despite the advantages that social media bring to the organizations, it may also involve risks and threats to businesses because they no longer control what customers say about the product / service, commercial treatment and long term.

\section{FRAMEWORK AND HYPOTHESIS}

In the current global economic environment, the ability to reach customers, interactivity and low cost associated with social media types make them even more attractive. However, not all organizations are active in this field and / or explore all possibilities.

In the last decade, the academic community has paid great attention to users of social media, while the business component has been less considered. Therefore, it is pertinent to deepen the study of the determinants of the decision makers regarding the use of social media and the process that leads them to adopt more active or less active presences on different social media sites. The model under study examines how organizational characteristics and perceptions influence the decision process and barriers to the use of social media in businesses. In this sense, the following hypotheses were constructed for testing in this study.

The first hypothesis is related to the involvement of organizations towards activities in social media that several authors [12], [18]. Hypothesis H1: The decision process about the involvement is influenced by perceptions that organizations have about social media. This was subdivided as shown in Table I. It is intended to test whether the involvement is influenced by perceptions that organizations have.

TABLE I. DIMENSIONS OF SUB HYPOTHESES OF H1

\begin{tabular}{|l|l|}
\hline \multicolumn{1}{|c|}{ Dimensions } & \multicolumn{1}{c|}{ Hypotheses } \\
\hline H1a: Motivation & $\begin{array}{l}\text { Involvement degree in social media is equal, on } \\
\text { average, for the different categories of motivation to } \\
\text { use these media. }\end{array}$ \\
\hline H1b: Benefits & $\begin{array}{l}\text { Involvement degree in social media is equal, on } \\
\text { average, for the different categories of benefits } \\
\text { perceived by organizations. }\end{array}$ \\
\hline H1c: Constraints & $\begin{array}{l}\text { Involvement degree in social media is equal, on } \\
\text { average, for the separate categories of difficulties } \\
\text { perceived by organizations. }\end{array}$ \\
\hline
\end{tabular}

The decision process is divided into the usual decision process of the engagement process, so that the hypothesis $\mathrm{H} 2$ : The decision making process is influenced by organizational characteristics" was subdivided into three sub-hypotheses. The decision process relating to the use of social media was studied by [19] in order to find differences in the use of these media in SMEs, where the type of customer was B2B. These authors used demographic characteristics of organizations, e.g., offer type, size and sales volume, as predictors of the decision process. The first subdivision of $\mathrm{H} 2$ is: The use of social media is influenced by demographic characteristics of the organizations. Table II lists constructors of this hypothesis.

TABLE II. DEMOGRAPHICS DIMENSIONS OF H2A

\begin{tabular}{|l|l|}
\hline \multicolumn{1}{|c|}{ Dimensions } & \multicolumn{1}{c|}{ Hypotheses } \\
\hline H2a1: Island & $\begin{array}{l}\text { The use of social media is equal, on average, for } \\
\text { the different islands. }\end{array}$ \\
\hline H2a2: Activity Sector & $\begin{array}{l}\text { The use of social media is equal, on average, for } \\
\text { the different sectors of activity. }\end{array}$ \\
\hline $\begin{array}{l}\text { H2a3: Enterprise } \\
\text { Dimension }\end{array}$ & $\begin{array}{l}\text { The use of social media is equal, on average, for } \\
\text { the different organizational dimensions. }\end{array}$ \\
\hline H2a4: Type of Client & $\begin{array}{l}\text { The use of social media is equal, on average, for } \\
\text { the different types of customers. }\end{array}$ \\
\hline H2a5: Offer Type & $\begin{array}{l}\text { The use of social media is equal, on average, for } \\
\text { the different offers types. }\end{array}$ \\
\hline
\end{tabular}

Regarding the decision process concerning the involvement in social media, it was understood to be relevant to the above process with the demographic characteristics of the organizations and was used in studies of [3], [20], as well as policies and strategies implemented, which were referenced in several studies [3], [21], [22], [23], [24], [20]. Thus, the second sub -hypothesis H2b is: Engaging in social media is influenced by demographic characteristics of organizations as showed in Table III.

TABLE III. DEMOGRAPHICS DIMENSIONS OF H2B

\begin{tabular}{|l|l|}
\hline \multicolumn{1}{|c|}{ Dimensions } & \multicolumn{1}{c|}{ Hypotheses } \\
\hline H2b1: Island & $\begin{array}{l}\text { Engaging in social media is equal, on average, for } \\
\text { the different islands. }\end{array}$ \\
\hline H2b2: Activity Sector & $\begin{array}{l}\text { Engaging in social media is equal, on average, for } \\
\text { the different sectors of activity. }\end{array}$ \\
\hline $\begin{array}{l}\text { H2b3: Enterprise } \\
\text { Dimension }\end{array}$ & $\begin{array}{l}\text { Engaging in social media is equal, on average, for } \\
\text { the different organizational dimensions. }\end{array}$ \\
\hline H2b4: Type of Client & $\begin{array}{l}\text { Engaging in social media is equal, on average, for } \\
\text { the different types of customers. }\end{array}$ \\
\hline H2b5: Offer Type & $\begin{array}{l}\text { Engaging in social media is equal, on average, for } \\
\text { the different offer types. }\end{array}$ \\
\hline
\end{tabular}

The third sub-hypothesis $\mathrm{H} 2 \mathrm{c}$ is defined as: The involvement in social media is a function of policies and strategies implemented as seen in Table IV.

Some researchers studied perceived barriers to the use of social media in SMEs [3], where the type of customer was $\mathrm{B} 2 \mathrm{~B}$. Thus, we sought to test if the barriers that prevent the use of social media are influenced by demographic characteristics of $\mathrm{B} 2 \mathrm{~B}$ organizations. We defined $\mathrm{H} 3$ : The barriers that constrain the use of social media are influenced by demographic characteristics of organizations as summarized in Table V. 
TABLE IV. STRATEgIC AND CORPORATE POLICIES DimENSIONS OF H2C

\begin{tabular}{|l|l|}
\hline \multicolumn{1}{|c|}{ Dimensions } & \multicolumn{1}{c|}{ Hypotheses } \\
\hline H2c1: Channels Used & $\begin{array}{l}\text { Engaging in social media is equal, on average, } \\
\text { for the various channels used. }\end{array}$ \\
\hline H2c2: Strategy & $\begin{array}{l}\text { Engaging in social media is equal, on average, } \\
\text { for different categories of strategy existence. }\end{array}$ \\
\hline $\begin{array}{l}\text { H2c3: } \text { Use of } \\
\text { Measurement Tools }\end{array}$ & $\begin{array}{l}\text { Engaging in social media is equal, on average, } \\
\text { for different categories of existence of } \\
\text { measurement to assess their presence in the } \\
\text { media. }\end{array}$ \\
\hline $\begin{array}{l}\text { H2c4: Human Resources } \\
\text { Affections }\end{array}$ & $\begin{array}{l}\text { Engaging in social media is equal, on average, } \\
\text { for the different kind of human resources } \\
\text { affects. }\end{array}$ \\
\hline H2c5: Time & $\begin{array}{l}\text { Engaging in social media is equal, on average, } \\
\text { for the different categories of time used on these } \\
\text { media. }\end{array}$ \\
\hline H2c6: Frequency & $\begin{array}{l}\text { Engaging in social media is equal, on average, } \\
\text { for the different frequency categories of social } \\
\text { media usage }\end{array}$ \\
\hline $\begin{array}{l}\text { H2c7: } \text { Activities } \\
\text { Undertaken }\end{array}$ & $\begin{array}{l}\text { Engaging in social media is equal, on average, } \\
\text { for the different categories of activities } \\
\text { performed in these media. }\end{array}$ \\
\hline H2c8: Investment Policy & $\begin{array}{l}\text { Engaging in social media is equal, on average, } \\
\text { for the different budget categories used in these } \\
\text { media. }\end{array}$ \\
\hline
\end{tabular}

TABLE V. DEMOGRAPHICS DIMENSIONS OF H3

\begin{tabular}{|l|l|}
\hline \multicolumn{1}{|c|}{ Dimensions } & \multicolumn{1}{c|}{ Hypotheses } \\
\hline H3a: Island & $\begin{array}{l}\text { The barriers preventing the use of social media are } \\
\text { alike, on average, for the different islands. }\end{array}$ \\
\hline H3b: Activity Sector & $\begin{array}{l}\text { The barriers preventing the use of social media are } \\
\text { equal, on average, for different sectors of activity. }\end{array}$ \\
\hline H3c: Dimension & $\begin{array}{l}\text { The barriers preventing the use of social media are } \\
\text { equal, on average, for the different organizational } \\
\text { dimensions. }\end{array}$ \\
\hline H3d: Type of Client & $\begin{array}{l}\text { The barriers preventing the use of social media are } \\
\text { equal, on average, for the different kind of } \\
\text { customers. }\end{array}$ \\
\hline H3e: Offer Type & $\begin{array}{l}\text { The barriers preventing the use of social media are } \\
\text { equal, on average, for the different types of offering. }\end{array}$ \\
\hline
\end{tabular}

The hypotheses described above reflect the study's aims to explore social media use by Azorean firms.

\section{Methodology AND Results}

After the extensive literature review and defining of the research methodology based on dimensions and variables described above, we applied a methodology consisting of four phases: 1- Sample definition; 2- Questionnaire developments; 3- Data collection; 4- Statistical analysis.

Based on the literature review, a questionnaire underwent a pre-test, which led to the reorientation of some questions. This study was conducted on companies in the Autonomous Region of the Azores, which is part of Portugal. There are two major reasons to analyze a region such as the Azores. The first is the fact that this region has a utilization rate of above average regarding the Internet in Portugal [25]. The second stems from the fact that the Azores are nine islands located in the middle of the North Atlantic, thus having a pronounced geographical isolation. So the sample gathered is composed of Azorean organizations in various sectors of activity and dimensions, which may or may not use social media. The type of sampling used was non-probability and, within this, snowball sampling.

Synthetic indices were created by a set of aggregate indicators that "measure" the constructors in the study and showed good feasibility. In a second phase, in an inferential analysis, we used a nonparametric Kruskal-Wallis test in order to validate the proposed conceptual model. The significance level used for inferential statistics was $5 \%$.

The period of data collection took place between January 30, 2013 and March 5, 2013. Solicitations were made to 1515 Azorean organizations and 259 questionnaires were obtained, resulting in a response rate of $17.09 \%$. However, 27 were considered invalid because they are incomplete, so the effective sample size was 232 .

Of the 232 organizations analyzed, $74 \%$ are now using social media. Of the remaining, $7.8 \%$ are planning to do so in the next 12 months and $18.1 \%$ did not intend to have a presence on social media. Regarding firms' size, based on the number of employees, $97.8 \%$ are SMEs, and the remaining $2.2 \%$ (5 organizations) are large organizations. Also, $60.5 \%$ have 1-9 workers, $31.4 \%$ have $10-49$ workers, $7 \%$ have between 50 and 249 employees and $1.2 \%$ have more than 250 staff. With regard to the locations of headquarters, most come from the island of São Miguel (67.24\%). If we add the island of Terceira, we have $78.02 \%$ of the organizations. Distribution of islands are as follows: Faial has $6.47 \%$ of the organizations, Pico and São Jorge have 4.31\%, And Santa Maria, Graciosa, Flores and Corvo, taken together, amount to about $7 \%$.

Businesses with a presence on social media belong to the following sectors of activity, tourism, services and trade; together these represent $78.5 \%$ of the organizations present. The sectors of manufacturing, media, telecommunications and information technology and other sectors represent values on the order of $7 \%$.

The tourism sector, with $36 \%$, was the one that had the largest number of organizations present on social media; within this, most organizations are in hospitality $(19.8 \%)$, followed by travel agencies, tour operators and animation tourism with $8.7 \%$ and restore / bar with $7.6 \%$.

Regarding the definition of a strategy for social media presence, more than three-quarters of Azorean organizations did not define a strategy. Only $18.6 \%$ of organizations have a defined strategy, $56.4 \%$ have a strategic direction and $25 \%$ have neither.

Synthetic indicators for the following dimensions were created:

- Digital media used - Index ranging from 1- used social medium to 2- social media not utilized. The reliability through Alfa Cronbach value is 0.598, which can be considered to be satisfactory [32]. Facebook has an average utilization of 1.05 , followed by LinkedIn with an average of 1.81. Sites with average use are the podcast sites Wikis and Pinterest, with an average of 1.99 
- Motivations for using Social Media - Index ranging from 1- not important to 5- very important. The reliability through Alfa Cronbach value is 0.834 , which can be thought to have good reliability [32]. The main motivation of firms using social media presence was "Reaching a wider audience" and "Increase sales" both with an average of 4.66 , followed by "Create brand awareness or product" with 4.51. "Recruit collaborators" with 2.57 and "Communicating with suppliers and partners" with 3.29 were average to poor.

- Benefits of the use of social media - Index ranging from 1- not relevant to 5- very relevant. The reliability through Alfa Cronbach value is 0.907 , which can be thought to have good reliability [32]. The main benefits of the companies with a presence on social media were "Increasing brand or product awareness" with an average of 4.56, followed by "Attract new customers", with 4.55 "Increase sales", with a 4.42 average. The benefits with the lowest averages were "Help in recruiting" of 2.88 and "Analyze competition" with 3.53 .

- Difficulties in exploring social media - Index ranging from 1- not relevant to 5- very relevant. The reliability through Alfa Cronbach value is 0.909 , which can be thought to have good reliability [32]. The main difficulties that companies encounter in the use of social media were "Measuring the impact on your business" with an average of 3.33, followed by "Availability or lack of resources", with 3.27 and "Integration with other marketing initiatives" with a 3.26 average. "Lack of support from top management of the organization" had an average of 2.51 and "Reluctance of managers to share information" was 2.63 .

- Barriers to adoption of social media - Index ranging from 1- not relevant to 5- very relevant. The reliability through Alfa Cronbach value is 0.804 , which can be thought to have good reliability [32]. The main barriers to the use of social media in business were "Loss of control of the message" with an average of 3.43, followed by "Lack of adaptation to company culture", with 3.40 and "Difficult to measure and monitor the benefits", with a 3.35 average. Less significant barriers were "Competitors are not using those assets" with an average of 2.30 and "These means are not important within the industry in which the organization operates" with 2.53

To test the hypotheses of the conceptual model, we used the nonparametric Kruskal-Wallis method. As seen in Table VI for H1, only benefits influence the degree of involvement, so the decision process regarding the involvement is not influenced by perceptions that organizations have, except for the perceived benefits.

TABLE VI. RESULTS OF KRUSKAL-WALLIS TEST FOR H1

\begin{tabular}{|c|c|l|}
\hline Hypotheses & P & \multicolumn{1}{|c|}{ Conclusion } \\
\hline H1a & 0,065 & Not rejected \\
\hline H1b & 0,004 & Rejected \\
\hline H1c & 0,354 & Not rejected \\
\hline
\end{tabular}

As can be seen in Table VII for H2a, the use of social media is influenced by demographic characteristics of organizations; however, the headquarters' location and main type of supply do not affect the use. For the latter hypothesis, if we had used a significance level of $10 \%$, the result would be different.

TABLE VII. RESULTS OF KRUSKAL-WALLIS TEST FOR H2A

\begin{tabular}{|c|c|l|}
\hline Hypotheses & \multicolumn{1}{|c|}{$\mathbf{P}$} & \multicolumn{1}{|c|}{ Conclusion } \\
\hline H2a1 & 0,256 & Not rejected \\
\hline H2a2 & 0,000 & Rejected \\
\hline H2a3 & 0,004 & Rejected \\
\hline H2a4 & 0,004 & Rejected \\
\hline H2a5 & 0,053 & Not rejected \\
\hline
\end{tabular}

As can be seen in Table VIII for H2b, the involvement of social media isn't influenced by demographic characteristics of the organizations. However, the main type of supply influences the involvement. Are summarized in Table IX, the hypothesis tests necessary for $\mathrm{H} 2 \mathrm{c}$ : The involvement of social media is influenced by policies and strategies implemented. The time of use on social media does not influence involvement.

TABLE VIII. RESULTS OF KRUSKAL-WALLIS TEST FOR H2B

\begin{tabular}{|c|c|l|}
\hline Hypotheses & \multicolumn{1}{|c|}{ P } & \multicolumn{1}{|c|}{ Conclusion } \\
\hline H2b1 & 0,093 & Not rejected \\
\hline H2b2 & 0,062 & Not rejected \\
\hline H2b3 & 0,587 & Not rejected \\
\hline H2b4 & 0,136 & Not rejected \\
\hline H2b5 & 0,050 & Rejected \\
\hline
\end{tabular}

Tests for hypothesis $\mathrm{H} 3$ are summarized in Table X. This hypothesis H3: The barriers that prevent the use of social media is not influenced by demographic characteristics of organizations, however, influences the type of customer barriers. 
TABLE IX. RESULTS OF KRUSKAL-WALLIS TEST FOR H2C

\begin{tabular}{|l|c|l|}
\hline Hypotheses & \multicolumn{1}{|c|}{ P } & \multicolumn{1}{|c|}{ Conclusion } \\
\hline H2c1 & 0,025 & Rejected \\
\hline H2c2 & 0,000 & Rejected \\
\hline H2c3 & 0,000 & Rejected \\
\hline H2c4 & 0,001 & Rejected \\
\hline H2c5 & 0,645 & Not rejected \\
\hline H2c6 & 0,000 & Rejected \\
\hline H2c7 & 0,000 & Rejected \\
\hline H2c8 & 0,000 & Rejected \\
\hline
\end{tabular}

TABLE X. RESUlts OF KRUSKAL-WALLIS TEST FOR H3

\begin{tabular}{|c|c|l|}
\hline Hypotheses & \multicolumn{1}{|c|}{ P } & \multicolumn{1}{|c|}{ Conclusion } \\
\hline H3a & 0,442 & Not rejected \\
\hline H3b & 0,070 & Not rejected \\
\hline H3c & 0,429 & Not rejected \\
\hline H3d & 0,045 & Rejected \\
\hline H3e & 0,765 & Not rejected \\
\hline
\end{tabular}

\section{DISCUSSION AND CONCLUSIONS}

Tourism is the sector of activity with greater adoption of social media, which is justified because it is an industry where the assets have a significant impact on consumer behavior, such as the choice of destination and planning the entire trip [26]. The sectors of agribusiness, construction, fuel distribution and transport were those with lower adherence.

The reasons that organizations cite for the use of social media are mainly related with reaching a wider audience, creating awareness, communicating with customers and increasing sales, which is consistent with the existing literature and other studies [3], [20], [27], [28]. A less prevalent reason is recruiting.

Organizations still perceive a significant number of benefits, particularly in terms of marketing and commercial. With regard to perceived difficulties, the most highlighted relate to the lack of resources and measure of the business impact (ROI), which is in agreement with some authors [29]. However, the absence of strategy and losing control of the message, which is not in agreement with existing literature, suggest that Azorean organizations are not obstacles to the success of their initiatives. The lack of support from top management and the reluctance of managers to share information is identified as the least impactual.

Through hypothesis testing, it was found that involvement is influenced only by the perceived benefits, which are in some way related to the above study by [5], which argues that engagement depends on the goals. In terms of usage, it was found that the variables of size, sector and type of client activity influence the utilization of social media, pointing in the same direction as the study [3].
With regard to the involvement, it was found that organizational demographic characteristics did not influence the degree of involvement, which does not corroborate with [5]. Policies and strategies influence the degree of involvement, which is in agreement with the results presented by this author.

\section{LIMITATIONS AND FUTURE RESEARCH}

We consider this study a step forward in analysis of the current status of social media in organizations and in confirming some of the findings in the literature review.

As observed in other countries and reported by several authors, there is a sizable group of companies that have already adopted social media [23], [24], [30], [31]. Most Azorean organizations analyzed use these resources, essentially preferring social networks like Facebook.

However, the results indicate that organizations still are at an early stage of involvement, allocating few human and financial resources. Firms using social media go directly to the implementation, neglecting strategy definition and monitoring.

Because of the vicissitudes deriving from a research project limited in time and in a limited geographic area, some limitations should be corrected in future investigations. The sample size and the kind of sampling do not guarantee that the findings are generally representative. Future work should consider larger samples.

As a continuation of this research, the inclusion of new independent variables would verify their influence on the dependent variables. It is important, for example, to include variables such as: the existence of an internal policy on the use of social media; top management support of employee participation in social media and analysis of productivity during working hours. It is also important to know how the use of social media in organizations is influenced by the number of hours per week spent using the media, how employees are affected by these resources, are these employees the people who manage online communities, and if this is done by people / organizations external to the firm.

Future studies should identify and analyze the reliability of: (1) the most commonly used metrics; (2) the tools used; (3) the frequency of use; (4) the difficulties perceived when using social media; and (4) if the results obtained are helping to achieve the goals set by organizations.

\section{REFERENCES}

[1] comScore, "It's a Social World: Top 10 Need-to-Knows About Social Networking and Where It's Headed -," 2011. [Online]. Available: http://www.comscore.com/por/Insights/Presentations_and_Whitepapers/2 011/it_is_a_social_world_top_10_need-toknows_about_social_networking. [Accessed: 09-May-2014].

[2] P. Kotler, H. Kartajaya, and I. Setiawan, Marketing 3.0: from products to customers to the human spirit. John Wiley \& Sons, 2010.

[3] N. Michaelidou, N. T. Siamagka, and G. Christodoulides, "Usage, barriers and measurement of social media marketing: An exploratory investigation of small and medium B2B brands," Ind. Mark. Manag., vol. 40, no. 7, pp. 1153-1159, Oct. 2011.

[4] K. Peters, Y. Chen, A. M. Kaplan, B. Ognibeni, and K. Pauwels, "Social Media Metrics - A Framework and Guidelines for Managing Social Media,”J. Interact. Mark., vol. 27, no. 4, pp. 281-298, Nov. 2013. 
[5] E. Constantinides and S. J. Fountain, "Web 2.0: Conceptual foundations and marketing issues," J. Direct, Data Digit. Mark. Pract., vol. 9, no. 3, pp. 231-244, Mar. 2008.

[6] T. O'Reilly, “What Is Web 2.0," 2005. [Online]. Available: http://oreilly.com/web2/archive/what-is-web-20.html. [Accessed: 17May-2014].

[7] P. R. Berthon, L. F. Pitt, K. Plangger, and D. Shapiro, "Marketing meets Web 2.0, social media, and creative consumers: Implications for international marketing strategy," Bus. Horiz., vol. 55, no. 3, pp. 261271, May 2012.

[8] Tiago, M.T., Veríssimo, J. "Digital Marketing and Social Media: Why bother?, Bus. Horiz., vol. 57, pp. 703-708

[9] J. Surowiecki, "The Wisdom of Crowds," Am. J. Phys., vol. 75, p. 336, 2005.

[10] L. Grossman, "You -- Yes, You -- Are TIME's Person of the Year TIME," Time, 2006. [Online]. Available: http://content.time.com/time/magazine/article/0,9171,1570810,00.html. [Accessed: 26-Jun-2014].

[11] Wikipedia, "You (Time Person of the Year)," 2007. [Online]. Available: http://en.wikipedia.org/wiki/You_(Time_Person_of_the_Year).

[12] J. Bernoff and C. Li, "The POST Method: A systematic approach to social strategy," $2007 . \quad$ [Online]. Available: http://forrester.typepad.com/groundswel1/2007/12/the-post-method.html. [Accessed: 26-Jun-2014].

[13] J. Bernoff, "Social Technographics: Conversationalists get onto the ladder," $2010 . \quad$ [Online]. Available: http://forrester.typepad.com/groundswell/2010/01/conversationalists-getonto-the-ladder.html. [Accessed: 26-Jun-2014].

[14] D. Evans, Social media marketing: An hour a day. 2008.

[15] T. Weinberg, The new community rules: Marketing on the social web. “ O’Reilly Media, Inc.,” 2009.

[16] L. S. L. Lai and E. Turban, "Groups Formation and Operations in the Web 2.0 Environment and Social Networks," Gr. Decis. Negot., vol. 17, no. 5, pp. 387-402, Jun. 2008.

[17] A. Richter, A. Stocker, S. Müller, and G. Avram, "Knowledge management goals revisited: A cross-sectional analysis of social software adoption in corporate environments," VINE, vol. 43, no. 2, pp. 132-148, 2013.

[18] G. Drury, "Opinion piece: Social media: Should marketers engage and how can it be done effectively?," J. Direct, Data Digit. Mark. Pract., vol. 9, no. 3, pp. 274-277, Mar. 2008.

[19] N. Michaelidou, N. T. Siamagka, and G. Christodoulides, "Usage, barriers and measurement of social media marketing: An exploratory investigation of small and medium B2B brands," Ind. Mark. Manag., vol. 40, no. 7, pp. 1153-1159, Oct. 2011.

[20] J. M. Veríssimo and G. Coimbra, "Marketing Digital em Portugal: Situação Actual e Tendências," 2011.

[21] D. E. R. Service, "Enterprise 2.0 - Harnessing social media," Deloitte, 2011. [Online]. Available: https://www.deloitte.com/assets/DcomCanada/Local Assets/Documents/ERS/ca_en_ers_enterprise_20_050611.pdf. [Accessed: 27-Jun-2014].

[22] H. B. R. A. Services, "the New Conversation: taking Social Media from talk to action," 2010.

[23] M. A. Stelzner, "2011 Social Media Marketing Report - How Marketers Are Using Social Media to Grow Their Businesses," Social Media Examiner, 2011. [Online]. Available: http://www.socialmediaexaminer.com/SocialMediaMarketingReport2011 .pdf. [Accessed: 27-Jun-2014].

[24] M. A. Stelzner, "2012 Social Media Marketing Industry Report - How Marketers Are Using Social Media to Grow Their Businesses," Social Media Examiner, 2012. [Online]. Available: http://www.socialmediaexaminer.com/SocialMediaMarketingIndustryRe port2012.pdf. [Accessed: 27-Jun-2014].

[25] INE, "Inquérito à Utilização de Tecnologias da Informação e da Comunicação nas Empresas 2012,” 2012.

[26] J. Miguéns, R. Baggio, and C. Costa, "Social media and Tourism Destinations: TripAdvisor Case Study," in Advances in Tourism Research, 2008, vol. 2008, pp. 1-6.

[27] F. Cipriani, "Mídias sociais nas empresas - O relacionamento online com o mercado," Deloitte, 2010. [Online]. Available: http://www.deloitte.com/assets/dcom-brazil/local assets/documents/estudos e pesquisas/apresentacao_midiassociais.pdf. [Accessed: 30-Jun-2014].

[28] Webmarketing123, “2012 State of Digital Marketing Report,” 2012.

[29] J. Evans, Dave; Mckee, Social media marketing: the next generation of business engagement. John Wiley \& Sons, 2010.

[30] M. A. Stelzner, "2013 Social Media Marketing Industry Report - How Marketers Are Using Social Media to Grow Their Businesses," Social Media Examiner, 2013. [Online]. Available: http://www.socialmediaexaminer.com/SocialMediaMarketingIndustryRe port2013.pdf. [Accessed: 27-Jun-2014].

[31] B. D. Weinberg and E. Pehlivan, "Social spending: Managing the social media mix," Bus. Horiz., vol. 54, no. 3, pp. 275-282, May 2011.

[32] R. A. Peterson, "A meta-analysis of Cronbach's coefficient alpha." Journal of consumer research, pp. 381-391, 1994. 